\title{
REVIEW
}

\section{The role of inspiratory muscle function and training in the genesis of dyspnoea in asthma and COPD}

\author{
Alison K. McConnell*
}

Sport Sciences Department, Brunel University, Uxbridge, Middlesex UB8 3PH, UK

Received 13 December 2004; accepted 14 March 2005

\section{KEYWORDS}

Inspirational muscle

training;

Exercise tolerance;

Dyspnoea;

Quality of life;

Rehabilitat on

\begin{abstract}
Summary The cardinal symptom of both asthma and CPRD is dyspnoea, and from a patient perspective, the most troublessme. Ghere are a multitude of inputs to the sensation of dyspnoea, few ot ivhit are readily modifiable. The level of inspiratory muscle v/prin or th butes to the sense of respiratory muscle effort and thence dysprica:a. Inspiratory muscle vork Felevated in patients with COPD and asilina due to hyperinflation and ain ircreased ventilatory requirement for exercise. Treatment teids co concertrate on reducing the load upon the inspiratory muscles Disc ed LV hy perinflation. Bronchodilators are the mainstay of treatment for COPD arid asthma; they reduce hyperinflation, inspiratory muscle loading and dyspnoea. In addition, programmes of pulmonary rehabilitation have an excellent evidence base for improving dyspnoea, exercise tolerance and quality of life. However, provision within the NHS is limited and not all patients are suitable. One component of pulmonary rehabilitation that can be implemented safely in a home-based setting is specific inspiratory muscle training (IMT). There is a strong theoretical rationale for IMT in patients with airway obstruction, which is also supported by empirical evidence. IMT offers a relatively accessible non-pharmacological treatment for dyspnoea that also improves exercise tolerance and quality of life.

( 2005 General Practice Airways Group. Published by Elsevier Ltd. All rights reserved.
\end{abstract}

\section{Contents}

Introduction

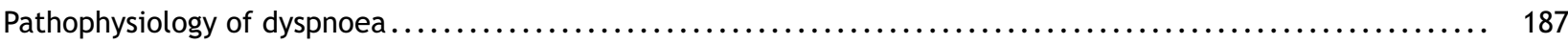

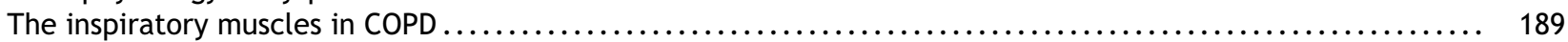

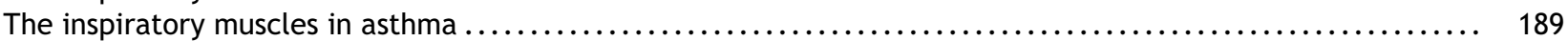

Management of dyspnoea: exercise and inspiratory muscle training $\ldots \ldots \ldots \ldots \ldots \ldots \ldots \ldots \ldots \ldots \ldots \ldots \ldots \ldots$

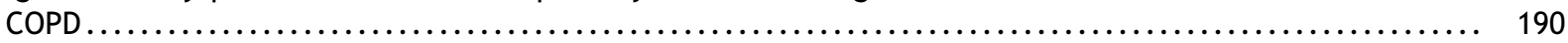

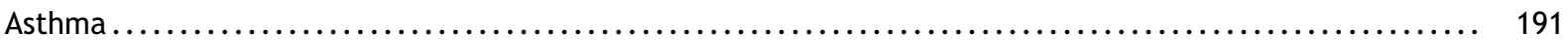

* Tel.: +44 1895 266480; fax: +44 1895269769.

E-mail address: alison.mcconnell@brunel.ac.uk. 


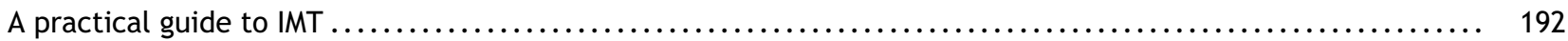

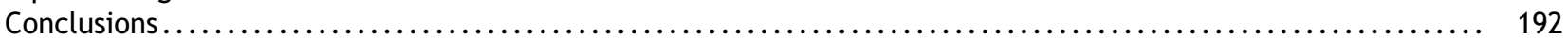

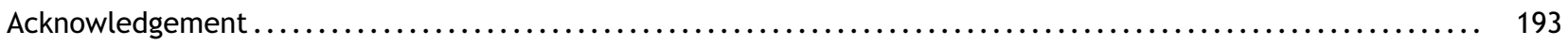

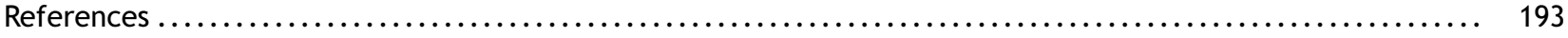

\section{Introduction}

Dyspnoea, exercise limitation and reduced quality of life are common features of obstructive pulmonary disease. Dyspnoea induces a progressive downward spiral that starts with physical inactivity. The resulting deconditioning can provoke social isolation, fear of dyspnoea and depression [1]. The multifactorial aetiology of dyspnoea has made it a 'difficult nut to crack' pharmacologically, but there is now a convincing body of evidence that structured programmes of physical exercise (rehabilitation) reduce dyspnoea, improve exercise tolerance, and enhance quality of life. This review will consider the pathophysiology of dyspnoea by focussing upon the role of inspiratory muscle function and ventilatory work in its genesis. It will also take a pragmatic view of the role of exercise training in the management of dyspnoea.

\section{Pathophysiology of dy:pho ear}

Sense of respiratory effort cont $i, i \in s$ lo exercise limitation in both healthy people and patients with respiratory disease [2]. To date, the only unifying hypothesis put forward to explain the mechanistic basis of dyspnoea is that proposed by Moran Campbell's group in the 1960s. Campbell coined the term 'length-tension inappropriateness' (LTI) to explain how the sensation of dyspnoea might be 'transduced' to consciousness [3]. Campbell argued that human beings have a quantitative, conscious appreciation of the degree of effort associated with breathing, and that dissociation or a mismatch between the central respiratory motor activity and the mechanical response of the respiratory system may produce a sensation of respiratory discomfort (dyspnoea). More recently, the LTI paradigm has been generalised to include not only afferent sensory inputs from respiratory muscles, but information emanating from receptors throughout the respiratory system [4]. When viewed in the context of the LTI paradigm, the role of respiratory muscle function and respiratory muscle work in the perception of dyspnoea becomes intuitively predictable in both respiratory patients and healthy people. Thus, the intensity of dyspnoea is increased when changes in respiratory muscle length (i.e., volume) or tension (i.e., pressure) are inappropriate for the outgoing motor command, or when the requirement for respiratory work becomes excessive. These conditions prevail in obstructive lung disease, where alterations in inspiratory muscle function and respiratory mechanics disturb the normal inter-relationship of motor outflow and the mechanical response to that outflow, creating inappropriateness. Similarly, physical deconditioning, inefficient breathing patterns, and gas exchange abnormalities, increase the ventilatory requirement for exercise, creating a high demand for respiratory muscle work. These conditions create a debilitating two-fold effect.

Suffice to say, Campbell's theory has not gone untested, and there have been a great many papers published in the intervening 40 years that have interrogated the neurophy iolpondal credibility of the LTI paradinm. The STI paradigm has largely stopdele test bf time and experimental scrutiny, and the reader is refe red to McConnell and Romer [5] for a rol-ectetailed critique of this literature, Oivich is beyond the scope of the current review.

There are two main factors that influence the magnitude of outgoing motor drive to the inspiratory muscles, and thence dyspnoeic sensation (respiratory effort sensation).

(1) the strength of the inspiratory muscles (their capacity to generate inspiratory pressure)

(2) the demand for inspiratory muscle work (the load placed on the inspiratory muscles)

Factors that reduce the strength (capacity) of the inspiratory muscles increase the magnitude of the motor drive required to generate a given change in lung volume, e.g., muscle fatigue (reduction in muscle strength that is reversible by rest). Similarly, motor drive is increased by factors that increase the demand for inspiratory muscle force, e.g., an increased ventilatory demand. It is important to appreciate that the intensity of dyspnoea is not completely explained by the magnitude of outgoing inspiratory motor drive. The quality of breathlessness is modulated by inputs from other receptors (chemoreceptors, Cfibres) [6]. However, there is no doubt that the magnitude of inspiratory motor drive plays a major role in determining the intensity of dyspnoea [7] in patients with COPD and asthma. 


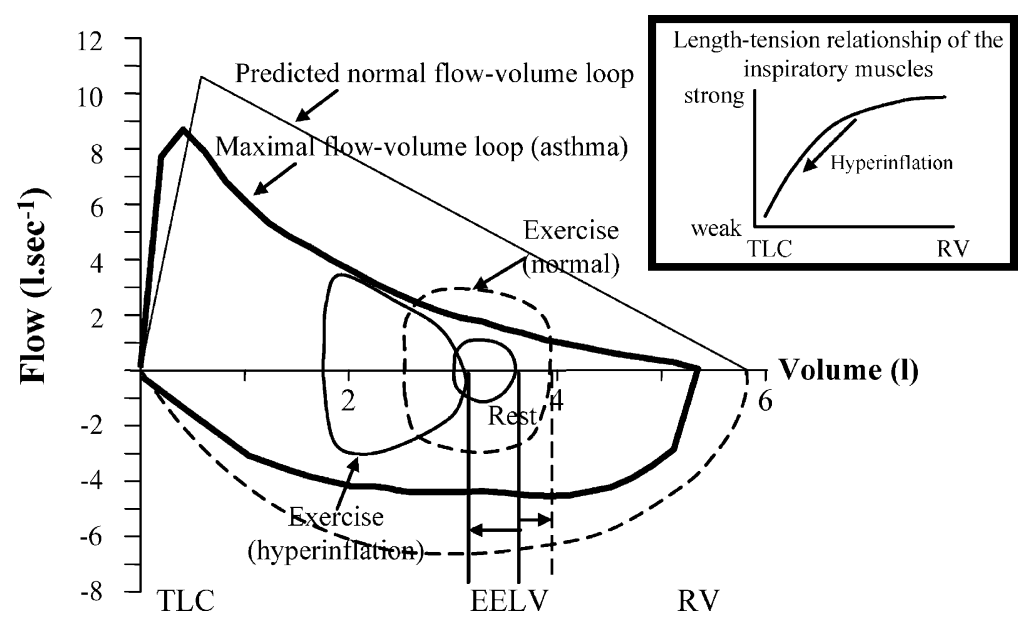

Figure 1 Comparison of the response of the exercise tidal flow volume in a person with asthma (solid lines), compared with that predicted for someone with normal lungs (dashed lines). Note that in the presence of expiratory flow limitation, the person with asthma must encroach upon their inspiratory capacity in order to increase minute ventilation (flow volume loop shifts to the left and end expiratory lung volume (EELV) increases). The person with normal lungs is able to increase minute ventilation by utilising both their inspiratory and expiratory reserve volumes (EELV decreases). The inset illustrates the length-tension relationship of the inspiratory muscles showing that as lung volume increases (as occurs in hyperinflation), the inspiratory muscles become weaker.

The single most important factor contributing to an increased requirement for inspiratory motor drive in COPD and asthma is likely to be the dynamic hyperinflation generated by expira ory flow limitation [8]. Figure a illostates how expiratory flow limitation ind prénature airuay closure stilnularean adaptive respensenthal shitts the tidal flow loop towards iocal ung capacity (TLC), increasing end expiratory lung volume (EELV). Hyperinflation affects both the capacity of the inspiratory muscles to generate pressure (see inset of Figure 1), and the demands placed upon them for inspiratory pressure generation. Although dynamic hyperinflation serves to maximise tidal expiratory flow under conditions of expiratory flow limitation (by moving the tidal flow loop away from the maximum envelope), there is a requirement to breathe at higher ranges of the total lung capacity (reducing inspiratory capacity) where the elastic load presented to the inspiratory muscles by the lungs and chest wall is higher. This creates a 'restrictive' ventilatory deficit. Hyperinflation and/or expiratory flow limitation also exacerbate inspiratory muscle loading in a number of further ways:

- by inducing functional weakening of the inspiratory muscles (see inset to Figure 1: diaphragm geometry is altered through foreshortening, which moves the inspiratory muscles to a weaker portion of their lengthtension relationship).
- by forcing inspiratory time to shorten (to allow more time for expiration, which moves the inspiratcrlyuscles to a weaker portion of lneil force-velosity relationship [the faster a musclecortiacts, the lower its force generating capacity]).

- by generating positive end expiratory pressure (PEEP - expiration ends before all of the forces acting on the lung are in equillibrium, so inspiration is initiated under a positive expiratory load).

Table 1 summarises the [obstructive] diseaserelated factors that influence the strength of the inspiratory muscles and the demand for inspiratory muscle work. All of these factors are potentially modifiable: through pharmacotherapy $(P)$ to reduce airway obstruction and hyperinflation; through physical exercise training (PET) to reduce the demand for ventilation; or through specific inspiratory muscle training (IMT) to increase the capacity of the inspiratory muscles to generate and sustain inspiratory activity.

The fundamental nature of the contribution made by inspiratory muscle function to the sensation of dyspnoea should make these muscles an obvious target for therapy. Indeed, this is to some extent the case, because routine pharmacotherapy in patients with airway obstruction is designed to minimise obstruction, and hence the load placed on the inspiratory muscles due to hyperinflation and increased flow resistance. 
Table 1 Disease-related factors that influence the magnitude of outgoing motor drive to the inspiratory muscles (IMT = inspiratory muscle training; $P E T=$ physical exercise training; $P=$ pharmacological). See text for further explanation of each factor.

\begin{tabular}{ll}
\hline Inspiratory muscle strength & Inspiratory muscle work \\
\hline Primary weakness (IMT) & Ventilatory requirement of the exercise (PET) \\
Length-tension relationship (IMT) & Degree of flow resistance (P) \\
Force-velocity relationship (IMT) & Degree of hyperinflation (P) \\
Fatigue resistance (IMT) & Positive end expiratory pressure (P) \\
\hline
\end{tabular}

The following sections will describe the condition of the inspiratory muscles, and the mechanical repercussions of COPD and asthma. The final sections will take a pragmatic view of the potential role of physical exercise training (PET) and specific inspiratory muscle training (IMT) in the management of patients with obstructive lung disease.

\section{The inspiratory muscles in COPD}

The hallmark of COPD is expiratory flow limitation, which results from reduced lung recoil and airway tethering in addition to intrinsic airway narrowing. Whilst the most obvious mechanic ai defect is obstruction during expiration, if enost important mechanical and sensory Corsequences are upon inspirat of Incernplete lung entiplying during airways obstruction result it dy hamic lung hyperinflation and its attendant consequences for the inspiratory muscles (see Figure 1).

Treatments that reduce hyperinflation have been shown to reduce dyspnoea significantly, e.g., bronchodilators [9], lung volume reduction surgery [10], and continuous positive airway pressure (CPAP) [11]. Thus, there is clear evidence that dyspnoea can be alleviated by reducing the load placed upon the inspiratory muscles. The important question is; how best to achieve this in a care system with finite resources?

Patients with COPD frequently have inspiratory muscle dysfunction, exhibiting weakness and reduced endurance [12]. However, there is also seemingly contradictory evidence that the inspiratory muscles of patients with COPD undergo a training adaptation in response to the chronic inspiratory loading conditions accompanying the disease [13]. The healthy diaphragm is composed predominantly of two types of muscles fibres; one with high endurance, but low power (Type I, $45 \%)$, and the other with low endurance, but high power (Type II, 55\%). Patients with long-standing COPD have an abnormally high proportion of the former (Type I, 64\%; Type II, 36\%), which is an adaptive response to continuous inspiratory muscle loading [13]. Patients with COPD are well adapted to generating low flow rates for long periods of time (such as at rest), but this adaptation robs them of the ability to generate the high pressures and flow rates required during exercise. In the same way that marathon runners cannot match the pace of sprinters or middle distance runners over short distances, patients with COPD cannot attain high levels of exercise hyperpnoea. Indeed, the adaptations described above do not appear to protect the inspiratory muscles of COPD patients from exercise-indurec '́atigue [14]. This is probably a funcion of the lower forcegenerating cababty or the inspiratory muscles in COPL[1:2], which reauires the muscle to work at a greater propdriciof fits maximum capacity during ereicjis

The demand for exercise ventilation in patients with COPD is elevated by their deconditioned state, their inefficient breathing pattern, and their gas exchange impairment. Deconditioning leads to a premature reliance upon anaerobic metabolism, which evokes a respiratory compensation for the resulting metabolic acidosis. The tachypnoeic breathing pattern increases the dead space/tidal volume ratio, which reduces alveolar ventilation and results in an increased requirement for minute ventilation. Gas exchange impairments contribute to an increased ventilatory requirement via the stimulation of chemoreceptors by the resulting hypercapnia and hypoxaemia.

Thus, the available evidence supports the notion that patients with COPD not only have relatively weak, fatigue-prone inspiratory muscles, but that they also have an increased demand for ventilatory work during exertion. The latter stems from the direct effects of hyperinflation upon respiratory mechanics, as well as an elevated demand for minute ventilation. All of these impairments to exercise tolerance can be alleviated by nonpharmacological interventions that strengthen the inspiratory muscles and/or reduce the ventilatory requirement (see Management of dyspnoea, below). 


\section{The inspiratory muscles in asthma}

The mechanical abnormalities in patients with asthma mimic closely those described in COPD; however, there are important differences. For example, there is less reduction in static lung recoil pressure and more widespread intrathoracic airway narrowing in asthma [15]. In addition, the increased airway collapsibility in patients with COPD is not seen in asthmatics. Finally, the reversible nature of airways obstruction in asthma results in relatively short-lived periods of stress upon the inspiratory muscles, which undoubtedly influences their capacity to adapt, as they appear to in patients with chronic pulmonary disease [13].

There is no clear consensus regarding the strength of the inspiratory muscles in patients with asthma compared to healthy people, but it is universally accepted that bronchoconstrictioninduced hyperinflation is associated with a functional deficit in inspiratory muscle strength (see inset of Figure 1) [16]. As is the case in COPD, the major mechanical consequences of airway narrowing are increased flow resistive work, increased elastic work and PEEP (resulting from dynamic lung hyperinflation), as we! as reduced dynamic lung compliance $(\mathrm{L} \mid 7$, 8]. Lougheed et al. [19' t u ed mechacholine induced trorichodoristiction to examinel Che interrelationship between honchoconstriction, hyperinflation and dyspnoea. Multiple regression analysis indicated that change in inspiratory capacity (an index of dynamic hyperinflation) was the most powerful predictor of dyspnoea during bronchoconstriction, accounting for $74 \%$ of the variance in perceptual ratings. These observations are supported by more recent evidence confirming that hyperinflation is a major determinant of dyspnoea in patients with asthma [20].

As is the case in COPD, the mechanical changes associated with bronchoconstriction most likely increase the intensity of dyspnoea via their effect upon the magnitude of inspiratory motor drive. Experimental support for this suggestion has come from Bellofiore et al. [21] who found that the strongest determinant of dyspnoea during methacholine-induced bronchoconstriction was respiratory motor drive $\left(\mathrm{P}_{0.1}-\right.$ mouth occlusion pressure), which explained $82 \%$ of the total variance in dyspnoea. Most recently, Binks et al. [22] reported that institution of mechanical ventilation during methacholineinduced bronchoconstriction and hyperinflation significantly reduced ratings of 'effort to breathe' in mild asthmatics.
In common with patients who have COPD, the aerobic fitness of patients with asthma is also generally low [23]. It is therefore likely that poor aerobic conditioning also contributes to an increased ventilatory requirement, exacerbating the demands placed upon the inspiratory muscles during exercise.

It is important to appreciate that patients with asthma do not experience bronchoconstriction as a single sensation. Airway narrowing is associated with sensations of both increased respiratory effort (load) and chest tightness, which are distinct from one another [24], and are probably transduced by different receptors [25]. However, the sensation that has been linked to exercise intolerance is respiratory effort, which suggests that this should be the focus of therapeutic interventions. As is the case in patients with COPD, the increased demand for inspiratory muscle work in patients with asthma can be alleviated by nonpharmacological interventions that strengthen the inspiratory muscles and/or reduce the ventilatory requirement (see below).

\section{Manage inentacis cyspnoea: exercise and inispiratory muscle training (i): $:$}

Therapeutic interventions that reduce operational lung volumes during exercise, either by improving lung emptying, or by reducing ventilatory demand (which delays the rate of dynamic hyperinflation), result in clinically meaningful improvement of exercise endurance and symptoms in disabled COPD patients [8]. Currently, the evidence-based options available to achieve improved lung emptying are bronchodilators, lung volume reduction surgery (LVRS) and continuous positive airway pressure (CPAP). The GOLD committee recommendations propose a stepwise approach to treatment based upon disease severity [26]. For all but stage III (severe) patients the only treatment recommended for improved lung emptying is bronchodilators. For patients at or above stage II (mild), the committee also recommends rehabilitation, which reduces ventilatory demand.

There is now overwhelming evidence that structured programmes of physical exercise (rehabilitation) reduce breathlessness and improve quality of life in patients with COPD. This is reflected in the recommendations of the latest NICE guidelines for management of COPD, which state that pulmonary rehabilitation 'should be made available to all appropriate patients'. The 
benefit of the exercise component of rehabilitation programmes is derived largely from the reduction in the ventilatory demand that physical training evokes [27]. This not only reduces the total demand on the inspiratory muscles, but also the degree of hyperinflation that exercise induces.

However, a British Thoracic Society survey [28] on pulmonary rehabilitation provision in the UK concluded that only $1.7 \%$ of the COPD patients who could benefit from pulmonary rehabilitation actually have access to it. Furthermore, although pulmonary rehabilitation is strongly recommended for patients with COPD, it is not always practical. Many patients with COPD have co-morbidities that render them unable to walk, including recent myocardial infarction and unstable angina.

Thus, despite the strong evidence base for exercise, the practicalities dictate that the mainstay of dyspnoea management of COPD patients remains bronchodilators. The other treatment options for reducing the load on the inspiratory muscles, whilst effective, are expensive (LVRS, CPAP) and not always available (e.g., rehabilitation programmes). This being the case, it is reasonable to turn to the other side of the capacity/demand equation and to consider the option of increasing the ability of the inspirato $y$ muscles to tolerate the increased load io ahich they are subjected. This rain (DE= achieved by specific resistan $-e$ tidining onhance the stans, th and fatigue-resistance of the ins prom roy muscles.

Specific inspiratory muscle training (IMT) can be applied either in combination with physical exercise, or as an independent intervention. IMT has also been applied very successfully in a homebased setting. Once a controversial treatment, IMT has now achieved a good evidence base, particularly in patients with COPD. The NICE COPD guidelines cite the conclusions of a metaanalysis on the effects of IMT in patients with COPD; Lotters et al. [29] examined 15 studies, seven of which incorporated measures of dyspnoea. Studies included in the analysis used randomised controlled trials and set training loads $\geq 30 \%$ of the maximum strength of the inspiratory muscles in the treatment group. The effect sizes for changes in dyspnoea during exercise and daily activities (assessed using Baseline and Transition Dyspnoea Indexes [BDI and TDI] - [30]) were statistically significant and the largest of any of the outcomes assessed. These findings add support to the earlier recommendations of the joint panel of the American College of Chest Physicians and the American Association of Cardiovascular and Pulmonary Rehabilitation [31]. In their appraisal of IMT, the ACCP/AACVPR considered not only physiological responses to IMT (e.g., respiratory muscle strength and lung function), but also clinical outcomes such as dyspnoea and exercise capacity. They concluded that in studies where inspiratory muscle strength was increased with training there was evidence to support a significant reduction in dyspnoea. Of the eight randomised and controlled studies of IMT that were reviewed by the AACP/AACVPR, three studies measured dyspnoea [32-34]; of these, two studies reported significant correlations between the improvement in inspiratory muscle strength and the improvement in dyspnoea ratings after IMT.

More recent studies provide further evidence that an increase in inspiratory muscle strength with IMT ameliorates respiratory effort sensations in patients with COPD. In these studies dyspnoea was quantified either during exercise [35-37], in response to a loaded breathing task [38,39], using the BDI/TDI $[37,40]$, or using the Chronic Respiratory Disease Questionnaire (CRDQ) [39]. All of these studies reported significant improvements in inspiratory muscle strength and respiratory effort sensation post-IMT. Furthermore in chose studies where post-IMT changes in (exticice colerance were assessed nos ( folind a significant improvement [35] $36,38-40]$.

Collectivel, it tived literature supports the the res tical racionale for IMT in patients with COPD, i.e., by increasing the capacity of the inspiratory muscles to generate force, the magnitude of inspiratory motor drive may be correspondingly reduced. Numerous controlled studies have now shown that dyspnoea is ameliorated following IMT. The statistically significant correlations between increases in inspiratory muscle strength and reductions in respiratory effort sensations observed in some studies [32,33] lend support to a causal link between these two factors.

\section{Asthma}

The role of rehabilitation in the management of asthma has received relatively little attention compared with the plethora of studies in COPD. Notwithstanding this, there is published evidence that exercise training reduces dyspnoea and improves aerobic fitness [41,42]. The role of exercise in improving quality of life and lung function in patients with asthma remains unclear [42]. The role of exercise in the management of asthma is complicated by the fact that intense exercise is a potent trigger of bronchoconstriction in around $90 \%$ of people with asthma [43]. Despite the fact that this response is readily managed using bronchodilators and/or inhaled corticosteroids 
[44], there is considerable reluctance on the part of many people with asthma to expose themselves to the risk (as they perceive it) of exercise [45]. This is reflected in the generally low levels of aerobic fitness reported in patients with asthma [23], and gives cause for concern with respect to the long-term health of children with the condition.

A notable feature of airway obstruction in asthma is the large inter-subject variation in the intensity of dyspnoea for a given fall in $\mathrm{FEV}_{1}$ [19]. Furthermore, recent evidence suggests that women experience higher levels of dyspnoea [46], poorer quality of life and more frequent hospital admission [47] than men. Weiner and colleagues [48] reasoned that this might be partially explained by the fact that women have weaker inspiratory muscles than men. Accordingly, the influence of gender and inspiratory muscle strength was examined by comparing the inspiratory muscle strength, perception of dyspnoea to threshold loads, and bronchodilator consumption of 22 male and 22 female asthmatic patients with mild-to-moderate bronchoconstriction $\left(\mathrm{FEV}_{1}>60 \%\right.$ of predicted) [47]. For the same $\mathrm{FEV}_{1}$ (\% of predicted), the women had significantly weaker inspiratory muscles, whilst dyspnoea and $\beta_{2}-$ agoninst consumption were significantly higher thitar. in the men. The women wers divided ig is two groups; half received IMT the rerna naer received sham-training 1 ter 20 deeks of IMT that ey la ised their inspiratory muscle strer s lovith that of the men $(+42 \%)$, dyspnoea and $\beta_{2}$-agonist consumption of the women in the IMT group decreased compared with the placebo group and were no longer different compared with the men. These findings support a role for the absolute strength of the inspiratory muscles in determining the intensity of dyspnoea.

In another study, Weiner and colleagues confirmed the strong interrelationship between inspiratory muscle strength, dyspnoea and bronchodilator consumption [48]. Although they observed no correlation between baseline measures of inspiratory muscle strength and intensity of dyspnoea in their sample of 30 patients, they observed a highly significant correlation between change in inspiratory muscle strength and change in the intensity of dyspnoea following IMT. Indeed, $93 \%$ of the variance in dyspnoea was accounted for by the improvement in inspiratory muscle strength.

An impressive feature of studies of IMT in patients with asthma is the reduction in $\beta_{2}$-agonist consumption that accompanies IMT. In the three studies from Weiner's group, this reduction has ranged from $38 \%$ to $78 \%$, being greatest in those with the highest baseline consumption $[49,47,50]$. Thus, IMT appears to be particularly helpful for patients with high levels of dyspnoea and $\beta_{2}$-agonist consumption.

However, a note of caution is warranted at this point, because there are a small group of patients with asthma for whom further reductions in the intensity of dyspnoea sensation may be life threatening. According to one study, around $26 \%$ of patients with asthma have abnormally low perceptions of dyspnoea [51]; this was associated with low consumption of medication, increased emergency department visits, hospitalizations, near-fatal asthma attacks, and deaths during follow-up [51]. A second study confirmed the association between near fatal asthma and low perceptions of dyspnoea, as well as blunted hypoxic sensitivity [52]. It would therefore be inappropriate to implement IMT in this sub-group. However, available evidence suggests that patients with normal or high sensation of dyspnoea do not become desensitised to bronchoconstriction following IMT. Weiner et al. [50] noted that IMT did not result in exaggerated ablation of dyspnoea, and concluded that IMT was safe, at least for use in patients with mild asthma. Further research is required to identify those patients w tim astnnal who are likely to derive the (s) atest Denefit from IMT.

tlithers, for patients with high perception of dyspnota, high corrsumption of medication, low leve sof physical activity, and mild asthma, IMT may offer the rare combination of an intervention that improves quality of life, whilst simultaneously reducing consumption of medication.

\section{A practical guide to IMT}

Successful outcomes of IMT have most commonly employed a technique of inspiratory muscle strength training known as pressure threshold training $[29,38,48,50,53-56]$. In pressure threshold IMT the user breathes in against a spring-loaded valve. The load (or weight) of the valve can be adjusted to accommodate a wide range of starting abilities, as well as the rapid improvements in strength that accompany training. Increases in strength of $25-40 \%$ are achievable within 4-6 weeks $[38,48,50,53-57]$. The training programme is simple, can be conducted in the patients' own home and with a minimal imposition upon their daily lives. A typical training programme consists of 30 breaths twice daily; this takes about 3 minutes per session (once in the morning and once in the evening) $[56,57]$. Because the intra-thoracic pressures that are generated are negative, the technique is very safe, and no adverse events have been reported to date. 


\section{Conclusions}

Dyspnoea is a complex, multifaceted symptom, but one whose mechanistic underpinnings appear to be best encapsulated in Campbell's LTI paradigm. Based on this paradigm, intensification of dyspnoea in obstructive pulmonary disease can be explained mechanistically by alterations in respiratory mechanics, and the corresponding 'inappropriateness' of the respiratory motor outflow. Acute and chronic improvements in the contractile properties of the respiratory muscles lead to reductions in the severity of exertional dyspnoea, most likely by reducing the level of inspiratory motor outflow. The mechanical and perceptual consequences of obstructive pulmonary disease provide a strong theoretical rationale for inspiratory muscle strengthening in patients with COPD and asthma.

The available evidence strongly supports the role of exercise training in the management of patients with COPD, although further research is required to assess its role in the management of asthma. The huge under-provision of rehabilitation services within the NHS means that the vast majority of COPD and asthma patients cannot access these services. Accordingly, IMT can bie viewed as a relatively accessible, evide nit. Dased component of rehabilitation prozranmes, that reduces dysp ooea iv proves exerrise tole concellind enhances quaticy of life in patiens with COPD. IMT is also suitable for treating asthma patients with high perceptions of dyspnoea and high consumption of medication.

\section{Conflict of Interest}

AKM declares a beneficial interest in the POWERbreathe ${ }^{\circledR}$ inspiratory muscle trainer in the form of a royalty share on license income to the University of Birmingham, as well as consultancy income from Gaiam Ltd.

\section{References}

[1] Ambrosino N, Strambi S. New strategies to improve exercise tolerance in chronic obstructive pulmonary disease. Eur Respir J 2004;24(2):313-22.

[2] Hamilton AL, Killian KJ, Summers E, Jones NL. Symptom intensity and subjective limitation to exercise in patients with cardiorespiratory disorders. Chest 1996;110(5):1255-63.

[3] Campbell EJM. The relationship of the sensation of breathlessness to the act of breathing. In: Howell JBL, editor. Breathlessness. London: Blackwell Scientific Publications; 1966. p. 55-64.
[4] ATS. Dyspnea: Mechanisms, assessment, and management: A consensus statement. Am J Respir Crit Care Med. 1999;159:321-40.

[5] McConnell AK, Romer LM. Dyspnoea in health and obstructive pulmonary disease: the role of respiratory muscle function and training. Sports Med 2004;34(2):117-32.

[6] Scano G, Ambrosino N. Pathophysiology of dyspnea. Lung 2002;180(3):131-48.

[7] O'Donnell DE, Bertley JC, Chau LK, Webb KA. Qualitative aspects of exertional breathlessness in chronic airflow limitation: pathophysiologic mechanisms. Am J Respir Crit Care Med 1997;155(1):109-15.

[8] O’Donnell DE. Ventilatory limitations in chronic obstructive pulmonary disease. Med Sci Sports Exerc 2001;33(7 Suppl):S647-55.

[9] Belman MJ, Botnick WC, Shin JW. Inhaled bronchodilators reduce dynamic hyperinflation during exercise in patients with chronic obstructive pulmonary disease. Am J Respir Crit Care Med 1996;153(3):967-75.

[10] Martinez FJ, de Oca MM, Whyte RI, Stetz J, Gay SE, Celli BR. Lung-volume reduction improves dyspnea, dynamic hyperinflation, and respiratory muscle function. Am J Respir Crit Care Med 1997;155(6):1984-90.

[11] O’Donnell DE, Sanii R, Giesbrecht G, Younes M. Effect of continuous positive airway pressure on respiratory sensation in patients with chronic obstructive pulmonary disease during submaximal exercise. Am Rev Respir Dis 1988;138(5):1185-91.

[12] Orozco-Levi $M$. Structure and firction of the respiratory muscles in palients witl COPD: impairment or adaptation? Eur Respi J Suppl 2003;46:41s-51.

[13] Levine S, Kaiscr C. Leferovich J, Tikunov B. Cellular adaplat 01: in trie diaphragm in chronic obstructive W. Linonary disease. N Engl J Med 1997;337(25):1799-806.

[14] Kyroussis D, Polkey MI, Keilty SE, et al. Exhaustive exercise slows inspiratory muscle relaxation rate in chronic obstructive pulmonary disease. Am J Respir Crit Care Med 1996;153(2):787-93.

[15] Pride NB, Macklem PT. Lung mechanics in disease. In: Fishman AP, editor. Handbook of Physiology. Bethesda, MD: American Physiological Society; 1986. p. 659-92.

[16] Weiner P, Suo J, Fernandez E, Cherniack RM. The effect of hyperinflation on respiratory muscle strength and efficiency in healthy subjects and patients with asthma. Am Rev Respir Dis 1990;141(6): $1501-5$.

[17] Lougheed DM, Webb KA, O'Donnell DE. Breathlessness during induced lung hyperinflation in asthma: the role of the inspiratory threshold load. Am J Respir Crit Care Med 1995;152:911-20.

[18] Martin J, Powell E, Shore S, Emrich J, Engel LA. The role of respiratory muscles in the hyperinflation of bronchial asthma. Am Rev Respir Dis 1980;121(3):441-7.

[19] Lougheed MD, Lam M, Forkert L, Webb KA, O’Donnell $D E$. Breathlessness during acute bronchoconstriction in asthma. Pathophysiologic mechanisms. Am Rev Respir Dis 1993;148:1452-9.

[20] Martinez-Moragon E, Perpina M, Belloch A, de Diego $A$, Martinez-Frances $M$. Determinants of dyspnea in patients with different grades of stable asthma. J Asthma 2003;40(4):375-82.

[21] Bellofiore S, Ricciardolo FL, Ciancio N, et al. Changes in respiratory drive account for the magnitude of dyspnoea during bronchoconstriction in asthmatics. Eur Respir $J$ 1996;9(6):1155-9.

[22] Binks AP, Moosavi SH, Banzett RB, Schwartzstein RM. "Tightness" sensation of asthma does not arise from 
the work of breathing. Am J Respir Crit Care Med 2002;165(1):78-82.

[23] Satta A. Exercise training in asthma. J Sports Med Phys Fitness 2000;40(4):277-83.

[24] Moy ML, Woodrow Weiss J, Sparrow D, Israel E, Schwartzstein RM. Quality of dyspnea in bronchoconstriction differs from external resistive loads. Am J Respir Crit Care Med 2000;162(2 Pt 1):451-5.

[25] Killian KJ, Watson R, Otis J, St Amand TA, O’Byrne PM. Symptom perception during acute bronchoconstriction. Am J Respir Crit Care Med 2000;162(2 Pt 1):490-6.

[26] Pauwels RA, Buist AS, Ma P, Jenkins CR, Hurd SS, GOLD Scientific Committee. Global strategy for the diagnosis, management, and prevention of chronic obstructive pulmonary disease: National Heart, Lung, and Blood Institute and World Health Organization Global Initiative for Chronic Obstructive Lung Disease (GOLD): executive summary. Respir Care 2001;46(8):798-825.

[27] Casaburi R, Porszasz J, Burns MR, Carithers ER, Chang RS, Cooper CB. Physiologic benefits of exercise training in rehabilitation of patients with severe chronic obstructive pulmonary disease. Am J Respir Crit Care Med 1997;155(5):1541-51.

[28] British Thoracic Society. http://www.lunguk.org/ downloads/BLF_pul_rehab_survey.pdf.

[29] Lotters F, van Tol B, Kwakkel G, et al. Effects of controlled inspiratory muscle training in patients with COPD: a metaanalysis. Eur Respir J 2002;20(3):570-7.

[30] Mahler DA, Weinberg DH, Wells CK, et al. The measurement of dyspnea. Contents, interobserver agreement, and physiologic correlates of two new clinical indexes. Chest 1984;85(6):751-8.

[31] American College of Chest Physicians/American Asacicic ciol] of Cardiovascular and Pulmonary lehaniltition fuimonary rehabilitation. Chest $1997: 1 ? .13 i 2-$ yo.

[32] Harver A Mante (1)A, Daudenspeck JA. Tarsected in: piratcry muscle training improves respir wr. un uscle function and reduces dyspnea in patients with chronic obstructive pulmonary disease. Ann Intern Med 1989;111(2):117-24.

[33] Lisboa C, Munoz V, Beroiza T, et al. Inspiratory muscle training in chronic airflow limitation: comparison of two different training loads with a threshold device. Eur Respir J 1994;7(7):1266-74.

[34] Larson JL, Kim MJ, Sharp JT, et al. Inspiratory muscle training with a pressure threshold breathing device in patients with chronic obstructive pulmonary disease. Am Rev Respir Dis 1988;138(3):689-96.

[35] Lisboa C, Villafranca C, Leiva A, et al. Inspiratory muscle training in chronic airflow limitation: effect on exercise performance. Eur Respir J 1997;10(3):537-42.

[36] de Lucas Ramos P, Rodriguez Gonzalez-Moro JM, Garcia de Pedro J, et al. Training of inspiratory muscles in chronic obstructive lung disease. Its impact on functional changes and exercise tolerance. Arch Bronconeumol 1998;34(2):64-70.

[37] Nield MA. Inspiratory muscle training protocol using a pressure threshold device: effect on dyspnea in chronic obstructive pulmonary disease. Arch Phys Med Rehabil 1999;80(1):100-2.

[38] Weiner P, Magadle R, Berar-Yanay N, et al. The cumulative effect of long-acting bronchodilators, exercise, and inspiratory muscle training on the perception of dyspnea in patients with advanced COPD. Chest 2000;118(3):672-8.
[39] Covey MK, Larson JL, Wirtz SE, et al. High-intensity inspiratory muscle training in patients with chronic obstructive pulmonary disease and severely reduced function. J Cardiopulm Rehabil 2001;21(4):231-40.

[40] Sanchez Riera H, Montemayor Rubio T, Ortega Ruiz F, et al. Inspiratory muscle training in patients with COPD: effect on dyspnea, exercise performance, and quality of life. Chest 2001;120(3):748-56.

[41] Ram FS, Robinson SM, Black PN. Effects of physical training in asthma: a systematic review. Br J Sports Med 2000 Jun;34(3):162-7.

[42] Ram FS, Robinson SM, Black PN. Physical training for asthma. Cochrane Database Syst Rev 2000;(2). CD001116.

[43] Lacroix VJ. Exercise-induced asthma. Physician Sport Med 1999;27:75-92.

[44] Rundell KW, Jenkinson DM. Exercise-induced bronchospasm in the elite athlete. Sports Med 2002;32(9):583-600.

[45] Clark CJ, Cochrane LM. Physical activity and asthma. Curr Opin Pulm Med 1999;5(1):68-75.

[46] Wijnhoven HA, Kriegsman DM, Snoek FJ, Hesselink AE, de Haan M. Gender differences in health-related quality of life among asthma patients. J Asthma 2003;40(2):189-99.

[47] Weiner P, Magadle R, Massarwa F, Beckerman M, Berar-Yanay $N$. Influence of gender and inspiratory muscle training on the perception of dyspnea in patients with asthma. Chest 2002;122(1):197-201.

[48] Weiner P, Magadle R, Beckerman M, Berar-Yanay N. The relationship among inspiratory muscle strength, the perception of dyspnea andinhated beta2-agonist use in patients with asthma/ Can Recpir $\mathcal{2}$ 2002;9(5):307-12.

[49] Weiner P, A-g (C) Y, Ganam R, Weiner M. Inspiratory miscle training in patients with bronchial asthma. Chest $1992 ; 102(5): 35 \%-61$.

[501 Wemer H, Berar-ranay N, Davidovich A, Magadle R, Weiner $\Lambda$. inspiratory muscle training in patients with mild asthma with high consumption of inhaled beta2-agonists. Chest 2000;117(3):722-7.

[51] Magadle R, Berar-Yanay N, Weiner P. The risk of hospitalization and near-fatal and fatal asthma in relation to the perception of dyspnea. Chest 2002;121(2):329-33.

[52] Kikuchi Y, Okabe S, Tamura G, et al. Chemosensitivity and perception of dyspnea in patients with a history of nearfatal asthma. N Engl J Med 1994;330(19):1329-34.

[53] Ramirez-Sarmiento A, Orozco-Levi $M$, Guell $R$, et al. Inspiratory muscle training in patients with chronic obstructive pulmonary disease: structural adaptation and physiologic outcomes. Am J Respir Crit Care Med 2002;166(11):1491-7.

[54] Weiner P, Magadle R, Beckerman M, Weiner M, Berar-Yanay $N$. Maintenance of inspiratory muscle training in COPD patients: one year follow-up. Eur Respir J 2004;23(1):615.

[55] Weiner P, Magadle R, Beckerman M, Weiner M, BerarYanay N. Comparison of specific expiratory, inspiratory, and combined muscle training programs in COPD. Chest 2003;124(4):1357-64.

[56] McConnell AK, Romer LM. Inspiratory muscle training in healthy humans: resolving the controversy. [Review]. Int J Sports Med 2004;25:284-93.

[57] Romer LM, MCConnell AK. Specificity and reversibility of inspiratory muscle training. Med Sci Sports Exerc 2003;35(2):237-44.

Available online at www.sciencedirect.com

science $\mathcal{d}$ Direct•

Available online at http://www.thepcrj.com 